\title{
Study on Shrinkage Characteristics and the Law of Crack Propagation of Compacted Red Clay
}

\author{
Kai sheng Chen ${ }^{1, a^{*}}$, Zhen Lu $u^{2, b}$ \\ ${ }^{1}$ School of Civil Engineering, Guizhou University Guizhou Guiyang China \\ ${ }^{2}$ School of Civil Engineering, Guizhou University Guizhou Guiyang China \\ achen_kaisheng@163.com, bu_zhenqiaosui@163.com
}

Key word:compaction ; red clay ; shrinkage deformation ; crack Characteristics

\begin{abstract}
The red clay has high moisture content, high plasticity, high void ratio and other special engineering properties, especially when the subgrade surface dehydrates, it shrinks and cracks, caused the subgrade to have some diseases. Taking the subgrade filling from Liupanshui inner Expressway as the research object,doing the shringkage test to the red clay,measuring the shrinkage deformation and the crack characteristics of the red clay during the shrinkage process, got the law of the shrinkage deformation and evolution of the crack of the red clay under shrinkage condition.
\end{abstract}

\section{Foreword}

Because the red clay has high moisture content, high plasticity, high void ratio and other special engineering properties, with the operation time of the highway growing,the subgrade and pavement has some diseases. The Guiyang-Zunyi Expressway,the Guiyang-Bijie Expressway and some other expressways have a lot of ruts. In the survey we also found that a large number of pavement cracks, the crack size is different and the crack shape is irregular, the most serious crack is the vertical crack casued by sink, the length of the crack is more than a hundred meters, the pavement also has large area subsidence, these all mainly casued by subgrsde subsidence. There also has some problems of different degrees of red clay in other roads has been built outside Guizhou province. Such as 107 National Highway in Moyang,the semi-rigid type base, the surface course and the cement pavement always appear crack, slab pumping and crack slab.During the construction of the Beijing Zhuhai Expressway between Moyang and Yizhang,using a lot of red clay to filling embankment near Yizhang,making the embankment surface appear serious shape crack and fissuring,he crack size is different, The maximum width is up to5-6 $\mathrm{cm}$, depth is up to $26 \mathrm{~cm}$. The fundamental reason of subgrade pavement cracking is the red clay shrink because of the $\mathrm{r}$ educe of water. So the research of the deformation of red clay has a practical significance on highway construction in red clay area.

\section{Basic physical properties of Red clay}

This experiment adopted by the soil samples taken from

Expressway third section. Soil characteristics as follows: brownish red, wet, the homogeneous soil, the compact structure, with certains small wormholes and the wholes of plant roots.,on the grain co mposition ,most is the silty clay. According to the Test methods of soils for Highway Engineering(JTG E40-2007), the basic physical properties of the soil is shown in table 1. 
Table1 Basic physical properties of red clay

\begin{tabular}{|c|c|c|c|c|c|}
\hline \multirow{2}{*}{ JTG E40-2007 } & $>0.075 \mathrm{~mm} / \%$ & \multicolumn{2}{|c|}{$0.075 \sim 0.002 \mathrm{~mm} / \%$} & \multicolumn{2}{|c|}{$<0.002 \mathrm{~mm} / \%$} \\
\cline { 2 - 6 } & 10.8 & \multicolumn{2}{|c|}{42.1} & \multicolumn{2}{|c|}{$\begin{array}{c}\text { Coefficient } \\
\text { of }\end{array}$} \\
$\begin{array}{c}\text { Optimum } \\
\text { moisture } \\
\text { content/\% }\end{array}$ & $\begin{array}{c}\text { Maximum } \\
\text { dry unit weight } \\
\mathrm{g} / \mathrm{cm}^{3}\end{array}$ & $\begin{array}{c}\text { Plastic } \\
\text { limit/\% }\end{array}$ & $\begin{array}{c}\text { Liquid } \\
\text { limit/\% }\end{array}$ & $\begin{array}{c}\text { coefficient } \\
\text { of } \\
\text { curvature }\end{array}$ \\
\hline 33.3 & 1.82 & 33 & 54 & 7.14 & 0.27 \\
\hline
\end{tabular}

\section{Testing Program}

(1)Sample Preparation:Using the proctor compaction test to make the sample which the degree of compaction is $85 \%$, the moisture content was $23 \%, 33.8 \%$ and $54 \%$. The sample's diameter is $150 \mathrm{~mm}$ and the height is $120 \mathrm{~mm}$.

(2)Put the needles:Putting the needles on the sample horizontal direction( $\mathrm{X}$ direction and $\mathrm{Y}$ direction)and vertical direction( $Z$ direction)

(3)The method of shrinkage test:Under the conditions of $105 \square$,putting the sample in oven,the drying times are $10 \mathrm{~min}, 30 \mathrm{~min}, 60 \mathrm{~min}, 120 \mathrm{~min}, 240 \mathrm{~min}, 480 \mathrm{~min}$.

(4)Calculation and Analysis:Measuring the space between the needles on the horizontal direction( $\mathrm{X}$ direction and $\mathrm{Y}$ direction)and vertical direction( $\mathrm{Z}$ direction), moisture content, the number of cracks、 the maximum width and maximum length of the crack.

\section{Test result}

Table2 The result of shrinkage test

\begin{tabular}{|c|c|l|l|l|l|l|l|}
\hline $\begin{array}{c}\text { Initial } \\
\text { moisture } \\
\text { content } \\
(\%)\end{array}$ & $\begin{array}{c}\text { Drying time } \\
\text { (min) }\end{array}$ & 10 & 30 & 60 & 120 & 240 & 480 \\
\hline \multirow{5}{*}{23} & $\begin{array}{c}\text { Variable quantity } \\
\text { Moisture content } \\
\text { after shrinkage(\%) }\end{array}$ & 22.86 & 22.08 & 17.68 & 12.65 & 10.05 & 8.65 \\
\cline { 2 - 8 } & X direction shrinkage(cm) & 0.15 & 0.32 & 0.44 & 0.76 & 0.98 & 1.05 \\
\cline { 2 - 8 } & Y direction shrinkage( cm $)$ & 0.14 & 0.33 & 0.45 & 0.75 & 0.98 & 1.03 \\
\cline { 2 - 8 } & Z direction shrinkage(cm) & 0.18 & 0.36 & 0.49 & 0.79 & 1.02 & 1.07 \\
\hline \multirow{5}{*}{33.8} & $\begin{array}{c}\text { Moisture content } \\
\text { after shrinkage(\%) }\end{array}$ & 32.76 & 31.44 & 22.35 & 15.36 & 11.85 & 9.21 \\
\cline { 2 - 8 } & X direction shrinkage(cm) & 0.17 & 0.35 & 0.47 & 0.77 & 1.01 & 1.09 \\
\cline { 2 - 8 } & Y direction shrinkage(cm) & 0.18 & 0.35 & 0.45 & 0.78 & 1.03 & 1.08 \\
\cline { 2 - 8 } & Z direction shrinkage(cm) & 0.20 & 0.38 & 0.50 & 0.81 & 1.05 & 1.12 \\
\hline \multirow{5}{*}{54} & $\begin{array}{c}\text { Moisture content } \\
\text { after shrinkage }(\%)\end{array}$ & 53.72 & 52.36 & 39.65 & 21.25 & 14.38 & 11.05 \\
\cline { 2 - 8 } & X direction shrinkage(cm) & 0.21 & 0.37 & 0.49 & 0.80 & 1.08 & 1.15 \\
\cline { 2 - 8 } & Y direction shrinkage(cm) & 0.23 & 0.36 & 0.51 & 0.79 & 1.11 & 1.15 \\
\cline { 2 - 8 } & Z direction shrinkage(cm) & 0.27 & 0.41 & 0.53 & 0.83 & 1.13 & 1.21 \\
\hline
\end{tabular}




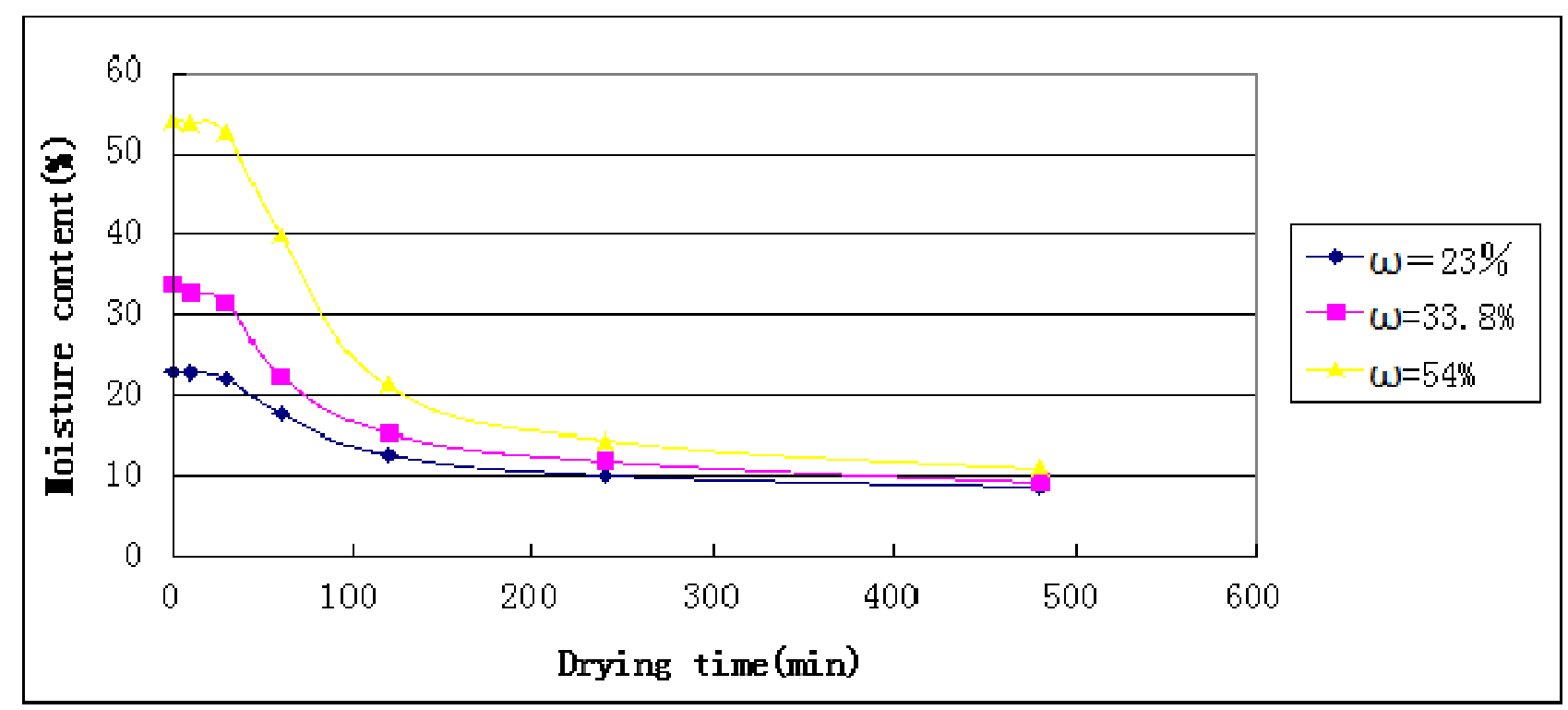

Figures.1 The relationship between moisture content and drying time

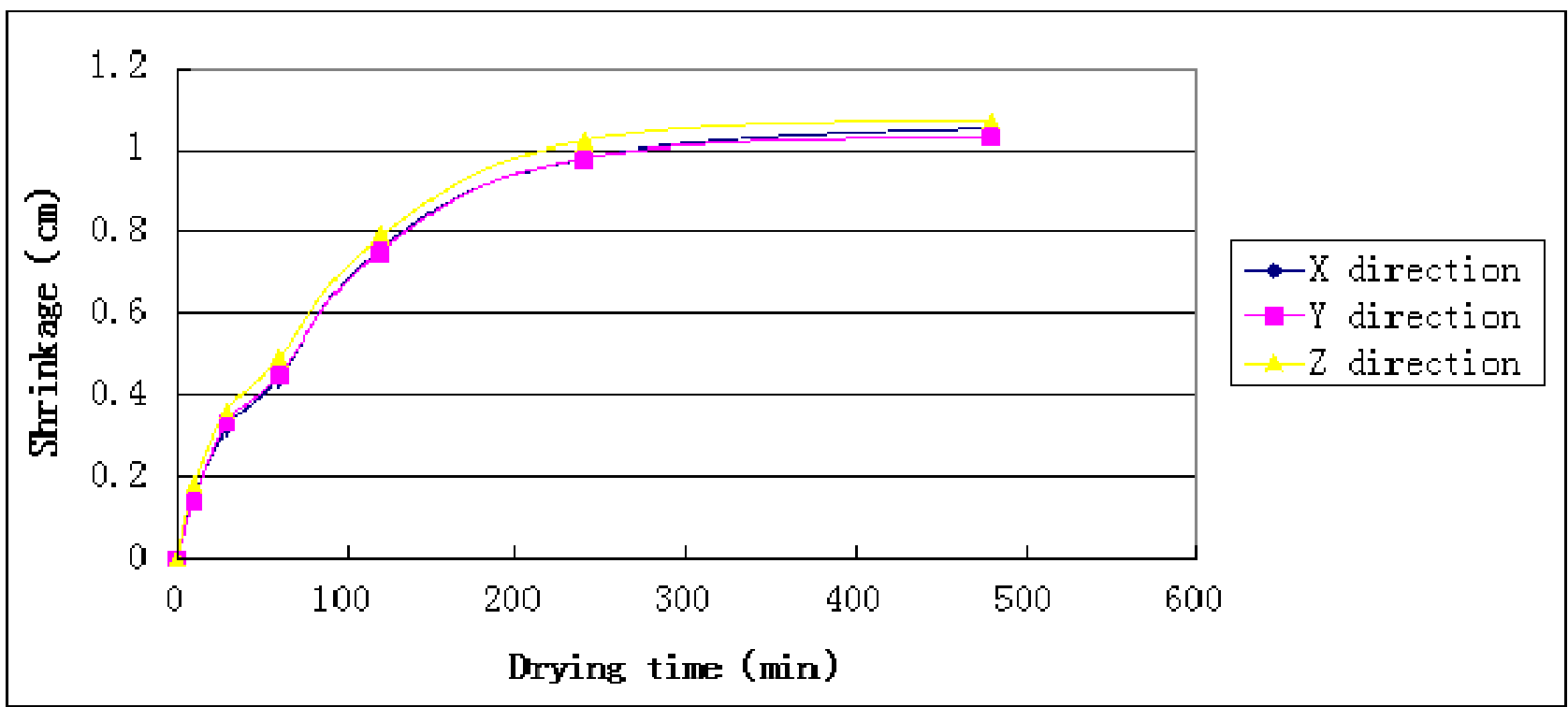

Figures. 2 The relation between shrinkage and drying time when $\omega=23 \%$

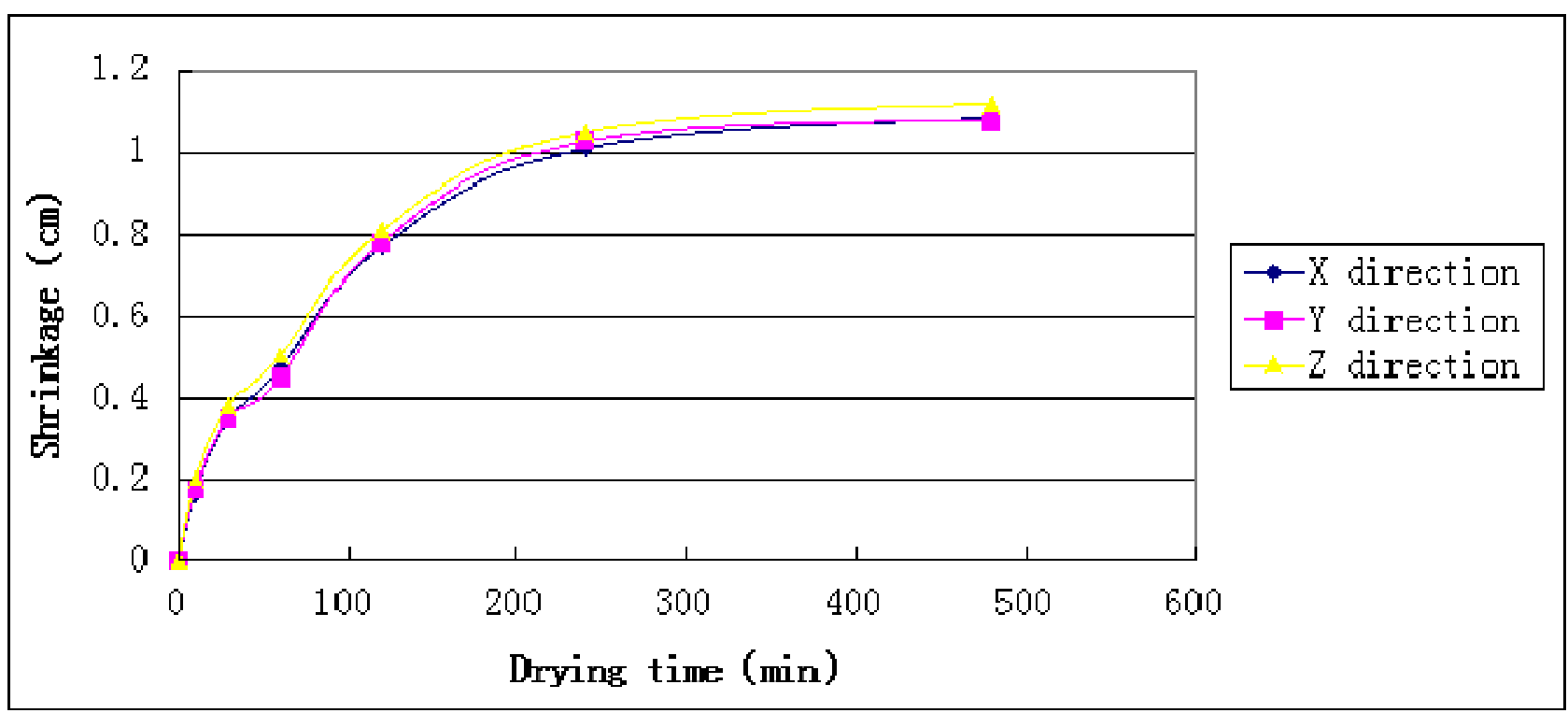

Figures. 3 The relation between shrinkage and drying time when $\omega=33.8 \%$ 


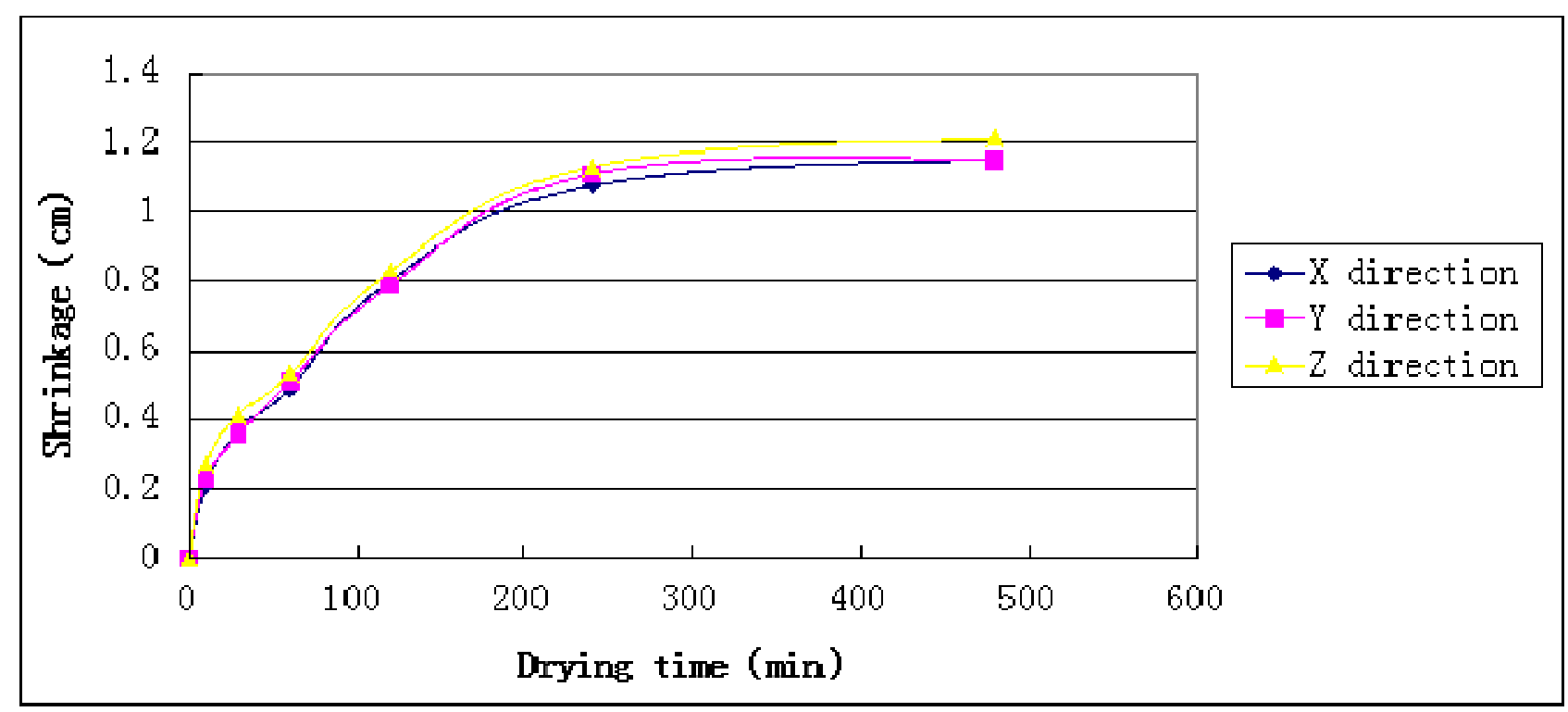

Figures. 4 The relation between shrinkage and drying time when $\omega=54 \%$

(1)The moisture content of the sample is reducing over drying time,before 240min, the moisture content of the sample was decreasing quickly,after 240min, it slow down. The higher the initial moisture content of the sample, the faster the moisture content decreasing.

(2)The shrinkage of the sample increasing over drying time,before 240 min, the sample shrinking very fast,after $240 \mathrm{~min}$, the sample shrinking very slow.

(3)The shrinkage in vertical direction is larger than the shrinkage in horizontal direction .

Table3 The relationship between cracks and time $(\mathrm{K}=85 \%, \omega=23 \%)$

\begin{tabular}{|c|c|c|c|c|c|c|c|}
\hline $\begin{array}{c}\text { Time } \\
(\mathrm{min})\end{array}$ & $\begin{array}{c}\text { Initial } \\
\text { moisture } \\
\text { content } / \%\end{array}$ & 30 & 60 & 120 & 240 & 360 & 480 \\
\hline \multirow{3}{*}{ Number } & 23 & 4 & 9 & 10 & 10 & 10 & 10 \\
\cline { 2 - 8 } & 33.8 & 1 & 2 & 2 & 3 & 3 & 3 \\
\cline { 2 - 8 } & 54 & 1 & 3 & 6 & 6 & 6 & 6 \\
\hline $\begin{array}{c}\text { Maximm } \\
\text { width } \\
(\mathrm{cm})\end{array}$ & 23 & 0.37 & 0.61 & 0.70 & 0.72 & 0.73 & 0.73 \\
\cline { 2 - 8 } & 33.8 & 0.24 & 0.36 & 0.47 & 0.52 & 0.55 & 0.58 \\
\hline $\begin{array}{c}\text { Maximm } \\
\text { length } \\
(\mathrm{cm})\end{array}$ & 23 & 0.26 & 0.37 & 0.48 & 0.53 & 0.55 & 0.55 \\
\cline { 2 - 8 } & 33.8 & 2.32 & 2.63 & 2.95 & 3.12 & 3.13 & 3.14 \\
\hline \multirow{2}{*}{} & 54 & 1.28 & 1.42 & 1.61 & 1.72 & 1.72 & 1.73 \\
\hline
\end{tabular}




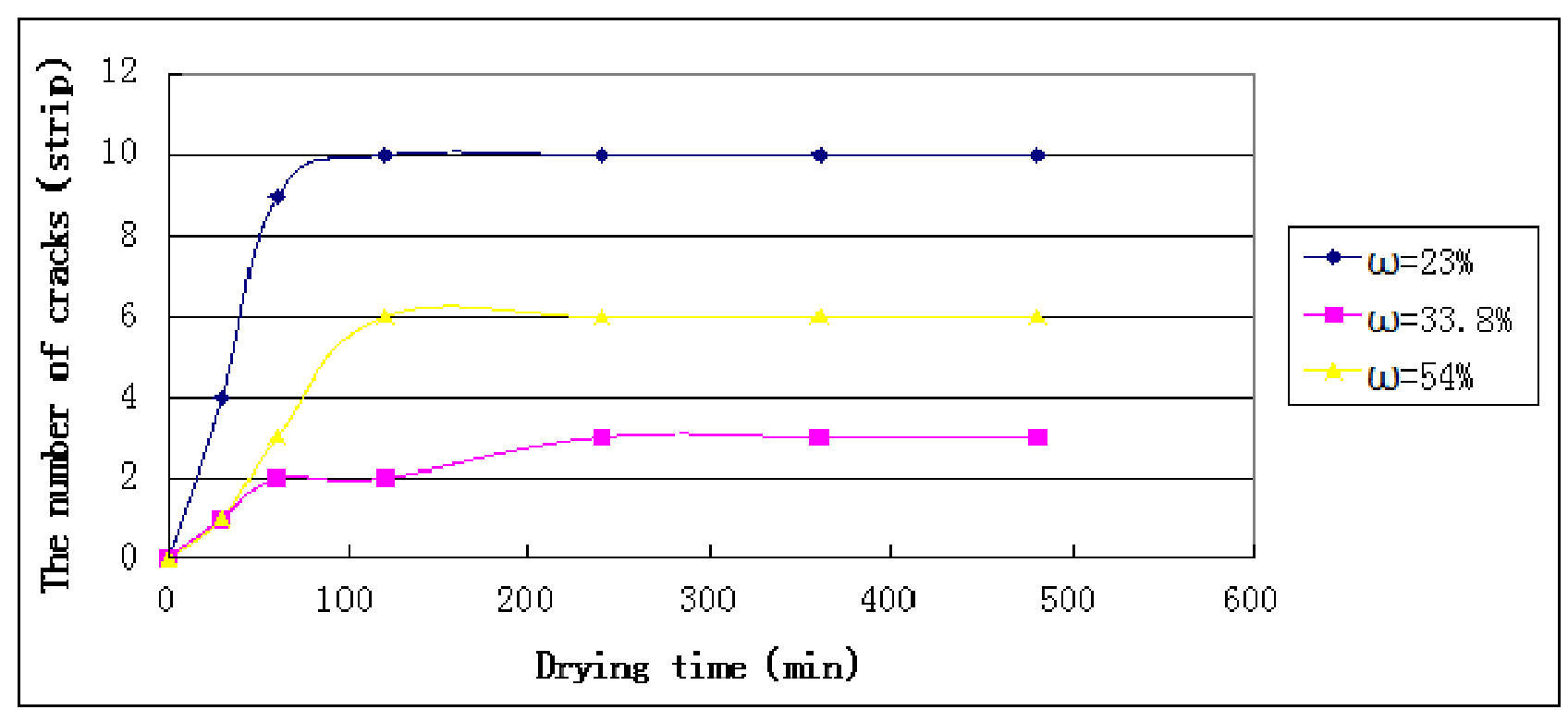

Figures.5 On the condition of different initial moisture content ,the number of cracks change over drying time when $\mathrm{K}=85 \%$

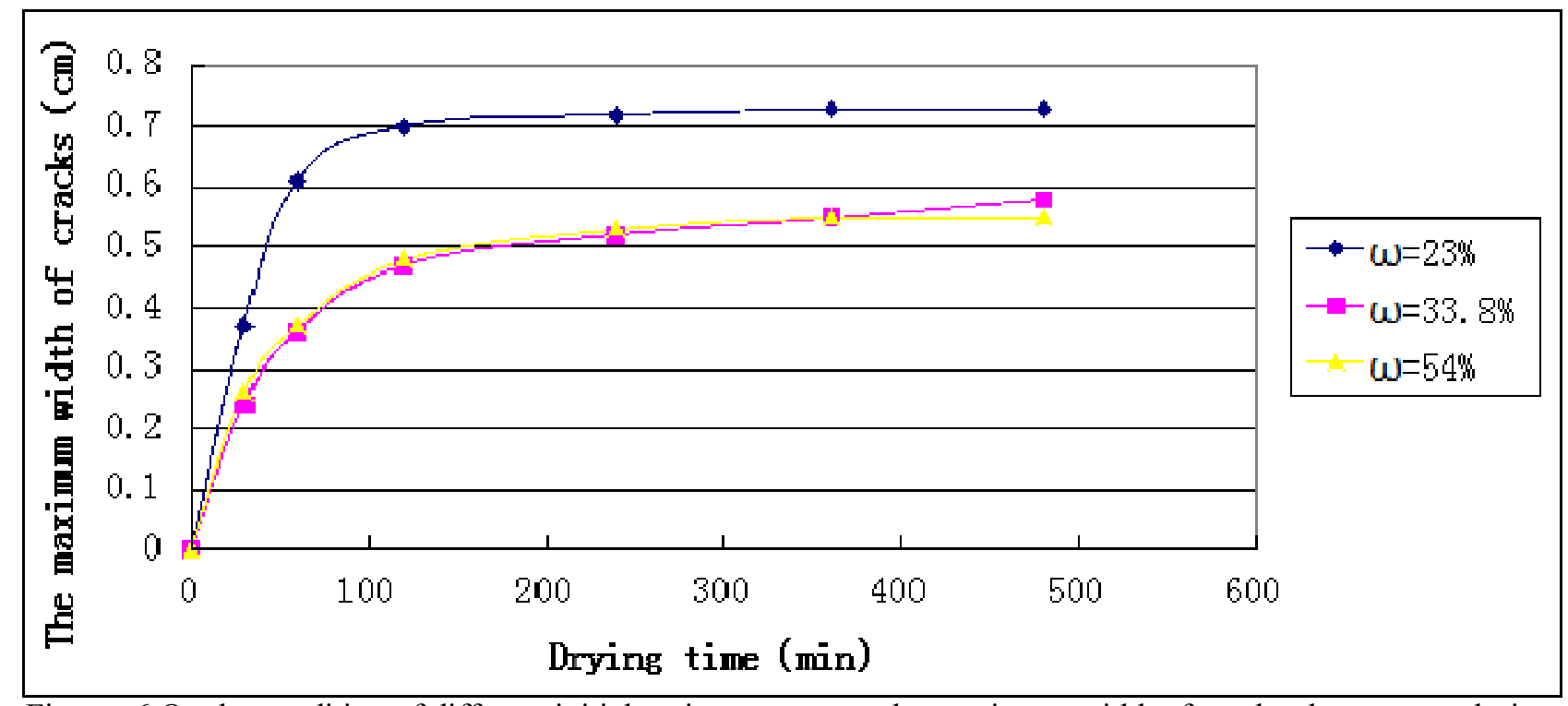

Figures.6 On the condition of different initial moisture content ,the maximum width of cracks change over drying time when $\mathrm{K}=85 \%$

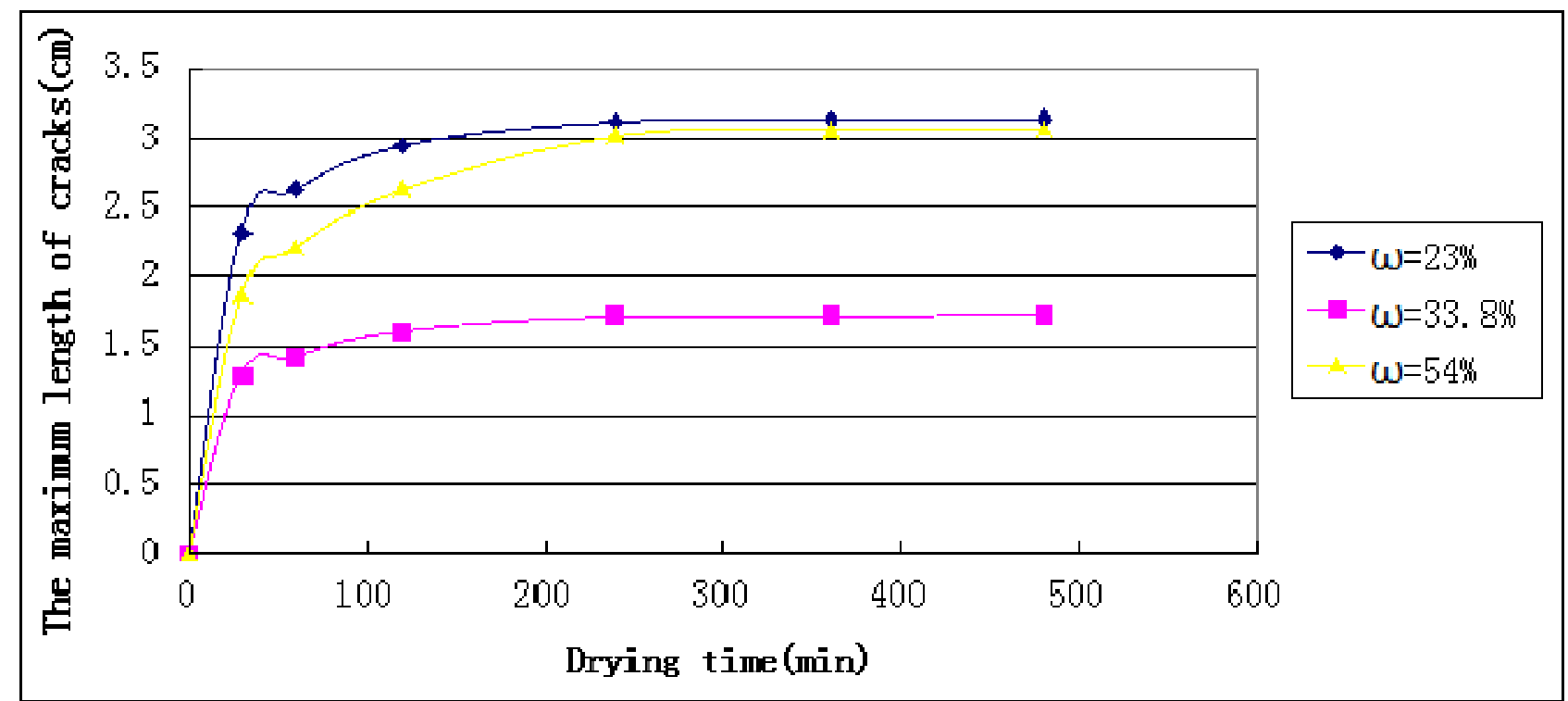

Figures.7 On the condition of different initial moisture content, the maximum length of cracks change over drying time when $\mathrm{K}=85 \%$ 
Form these pictures:

(1)Before120min, the growth rate of the number of cracks , the maximum width of cracks and the maximum length of cracks over drying time is big,after $120 \mathrm{~min}$, the growth rate is little.

(2)The lower the initial moisture content is, the number of cracks , the maximum width of cracks and the maximum length of crack is more(bigger).It's appear as the lower the initial moisture content is, the crack is more obvious .

\section{conclusion}

(1)The moisture content of the sample is reducing over drying time,before 240min, the moisture content of the sample was decreasing quickly,after 240min, it slow down. The higher the initial moisture content of the sample, the faster the moisture content decreasing.

(2)The shrinkage of the sample increasing over drying time,before 240min, the sample shrinking very fast,after $240 \mathrm{~min}$, the sample shrinking very slow.

(3)The shrinkage in vertical direction is larger than the shrinkage in horizontal direction .

(4)Before120min, the growth rate of the number of cracks, the maximum width of cracks and the maximum length of cracks over drying time is big,after $120 \mathrm{~min}$, the growth rate is little.

(5)The lower the initial moisture content is, the number of cracks, the maximum width of cracks and the maximum length of crack is more(bigger).It's appear as the lower the initial moisture content is, the crack is more obvious .

\section{Acknowledgements}

This work was financially supported by National Natural Science Foundation of China (Approval number:51368010)and Guizhou science and Technology Department-Guizhou University Foundation(Qiankehe Lh zi[2014]).

\section{References}

[1] Test Methods of Soils for Highway Engineering.(JTG E40-2007)

[2] Shengjun Wu.Study on Moisture Migration Regularity Test of Red Clay Subgrade[D]. Master Degree Thesis of Changsha University Science and Technology,2010.4

[3] Wenping Tao.Research on Design and Construction Technology of Red Clay Subgrade in South China[D].Master Degree Thesis of Changsha University Science and Technology,2010.4

[4]Xianjie Mu,Xiaoping Zhang. Research on mechanical properties of expansive soil under wetting-drying cycle[J] . Rock and Soil Mechanics , 2008 , (28)Supplement: 580-582

[5]Heping Yang,Rui Zhang,Jianlong Zheng. Variation of deformation and strength of expansive soil during cyclic wetting and drying under loading condition. $[\mathrm{J}]$. Chinese Journal of Geotechnical Engineering. 
